\title{
A Comparative Analysis of Grade 3 Students' Activities Before and During the COVID-19 Pandemic
}

\author{
Maria Christine M. Morada \\ Grade School Reading Teacher, De La Salle Santiago Zobel School, Philippines.
}

\begin{abstract}
How to cite this paper: Maria Christine M. Morada. (2021). A Comparative Analysis of Grade 3 Students’ Activities Before and During the COVID-19 Pandemic. The Educational Review, USA, 5(7), 226-231. DOI: $10.26855 /$ er.2021.07.006
\end{abstract}

Received: June 16, 2021

Accepted: July 10, 2021

Published: July 28, 2021

Corresponding author: Maria Christine M. Morada, Grade School Reading Teacher, De La Salle Santiago Zobel School, Philippines.

Email: christine.morada@dlszobel.edu.ph

\begin{abstract}
We have been living in a new world since the first quarter of 2020 due to the coronavirus pandemic. This condition presents a slew of new obstacles for individuals, groups, and entire communities. One of them is free time and the various ways to spend it. Therefore, the research aimed to analyze students' activities during free time before and during the COVID-19 pandemic. This research also evaluated whether there were any differences when certain factors affecting individual's environments were restricted. The research also looked at changes and perceptions of the students of fun and creative activities that can be done before and during the pandemic. To obtain more reliable data, the researcher used the triangulation technique, in which the data were evaluated using several resources. An electronic survey through G-forms, interview results and researcher's observations were used for the data gathering. The research participants were chosen purposively, coming from two sections in Grade $3(n=43)$. The researcher used qualitative descriptive analysis in interpreting the results from the gathered data. The research results indicated significant differences in students' activities before and during the COVID-19 pandemic, especially with activities involving physical, craft, and critical thinking. Students were more likely to choose activities that involve different movements and activities that spark their interest. This study only focuses on the students, involvement of the teachers and parents in the next cycle. The research may help the stakeholders to gain a new perspective of fun and creative ways to improve activities for Grade 3 students, especially in this better normal.
\end{abstract}

\section{Keywords}

Free Time Activities, Grade 3 Students, COVID-19 Pandemic

\section{Introduction}

The novel coronavirus disease (COVID-19) has afflicted the entire world. Individual habits were altered due to the immediate protective limitations imposed by governments, which also included complete city lockdowns, travel bans, local social gatherings, and school suspensions.

When it comes to making physical activity a regular habit, the elements that may be related have been studied in depth (Bauman et al., 2002). Ecological models are considered one of the most significant theoretical approaches to analyzing habit formation (McLeroy et al., 1988). These models establish that social and environmental factors are de- 
terminants in forming and maintaining physical activity habits (Salis et al., 2006).

The COVID-19 outbreak forced many to stay at home. There are guidelines in the Philippines for going outside to engage in social activities from March 2020 to May 2021. This provided an excellent chance to evaluate the activities of the Grade 3 students before and during the lockdown. Experts' recommendations on activities that can be done during a pandemic are taking active breaks, getting up and walking around the house, and doing online workouts (Ricci et al., 2021).

Students had to continue attending classes online, and their social lives were limited due to the prohibition on going outside. During the lockdown, different activities could have been an opportunity during free time that could have decreased. A considerable amount of research has been allotted to students' activities during a pandemic, but little research has been done to compare the students' activities before and during the pandemic. The hypothesis put forward was that students' activities differ during lockdown since they were confined to their homes and that their physical activity would have decreased since they could not go outside.

In the present study, the researcher focuses on shedding light on the activities Grade 3 students did before and during the COVID-19 pandemic. To broaden the approach, as a secondary aim, the researcher also wanted to look at changes and perceptions of fun and creative activities that can be done before and during the pandemic. The researcher aimed to evaluate whether there were any differences when certain factors affecting individual's environments were restricted.

Piaget (1954) believed the concrete stage, ages seven to eleven, is a crucial turning point in a child's cognitive development since it marked the beginning of logical or operational cognition. The child is now old enough to employ logical thought or processes (i.e., rules) but can only apply logic to physical things.

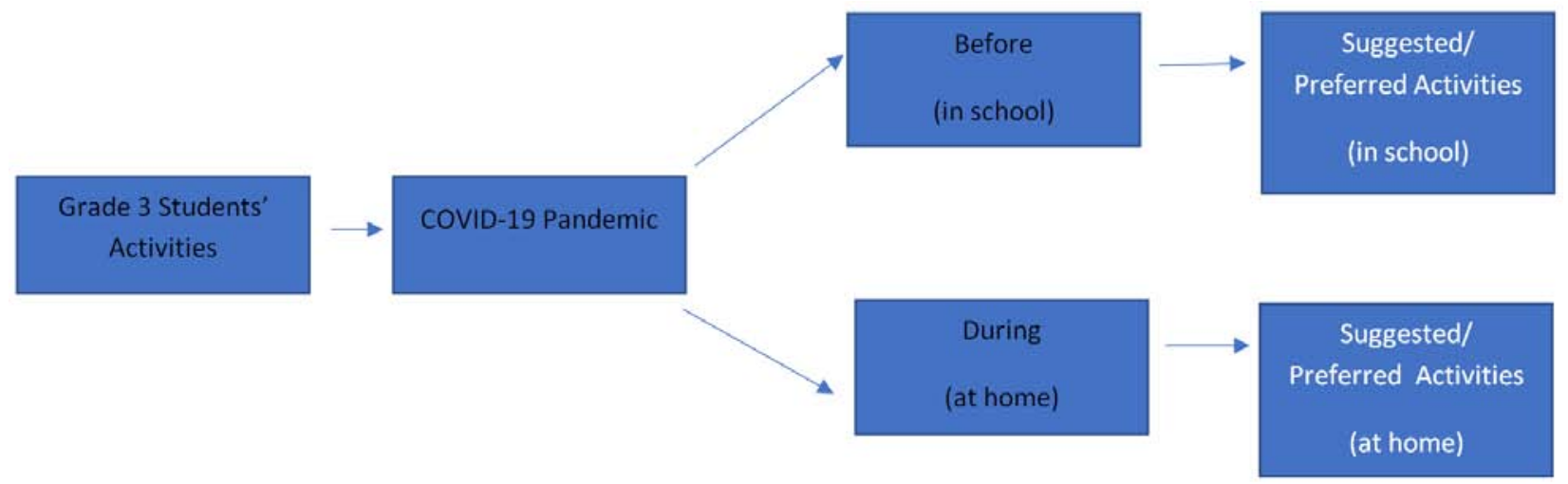

Figure 1. A Comparative Analysis of Grade 3 Students’ Activities Before and During the Covid-19 Pandemic.

The research questions are the following:

R1. What are the students' activities during their free time before the pandemic in school and at home?

R2. What are the students' activities during their free time during the pandemic at home?

R3. What are the students' perceptions of a creative and fun way of spending their free time before and during the pandemic?

\section{Methodology}

This chapter outlines the researcher's empirical designs and methodologies for analyzing Grade 3 students' activities during their free time before and during the COVID-19 pandemic at the De La Salle Santiago Zobel School.

\subsection{Research Design}

This study employed qualitative descriptive research. The investigation focuses on what happened rather than how or why something happened. As a result, observation and survey tools are frequently utilized to collect data (Gall et al., 2007). The researcher's task was to gather responses from Grade 3 pupils through a survey and interviews. The information gathered was accurately presented to the reader.

\subsection{Data and Data Gathering Procedure}

Data were collected using an electronic survey through Google forms. The online survey is a convenient way to collect data from a large cohort answering the same questions (de Vaus, 1995), and it is one of the widely used survey methods (Walter, 2010). It is convenient in a sense that different types of data on different topics can be collected elec- 
tronically from different respondents (Jansen et al., 2007) in a short time and at little or no cost (Czaja \& Blair, 2005).

The researcher elicited 43 responses from the online survey on Grade 3 students' activities during their free time before and during the COVID-19 pandemic. The survey was opened on 12 of May 2021 until 18 May 2021. The survey included four questions on the students 'experiences, perceptions, and suggestions of fun and creative activities; this was posted in the schools' learning management system (LMS) seesaw.

An interview was conducted the first week of June; this will be through Google meet. The researcher will invite six students for the focus group discussion. Here are the questions are the questions asked in the focus group discussion:

1. How would you describe your activities before the pandemic/during the pandemic? Explain your answer.

2. Which do you prefer: activities before the pandemic or activities during the pandemic? Explain your answer.

3. What are some fun and creative activities you can do with and without a pandemic? Explain your answer.

\subsection{Analysis of Data}

The researcher applied the triangulation technique where the data were analyzed through multiple resources to get more reliable information.

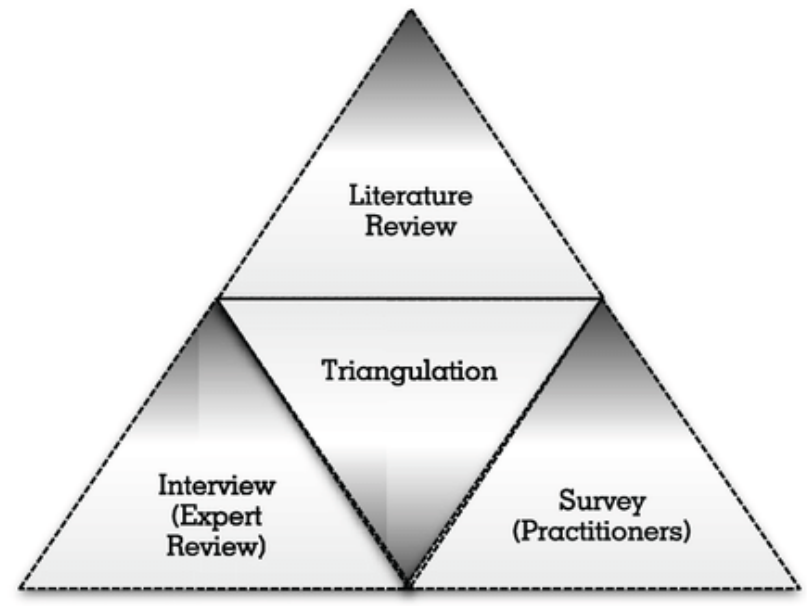

Figure 2. Triangulation Method.

\section{Results and Discussion}

The descriptive analysis carried out on the research provides an overview of the comparative data on Grade 3 students' activities during their free time before and during the pandemic. The results of the analysis are as follows.

Students were given a checklist to answer through G-Forms. The researcher identified four lists for the students to choose from for the first question. These activities are: play with my friends in the playground, go to the library, go to the canteen and others (should they select other, they must specify an activity or activities they do). The response descriptions for the four activities are shown in Figure 3.

R1: Figure 3 shows that the activity most often carried out in school during the students' free time before the pandemic was when the students chose to play with friends in the playground and go to the library. In addition, the activity just playing with friends in the playground also got enough portion of the students' activities. In fact, almost all the respondents chose playing with friends in the playground. However, a student answered, "Nothing, but eat watch sleep and play". The researcher asked the student to explain his answer and said he misunderstood the question.

The results indicated above that students' activities in school during their free time generally was playing with their friends in the playground. Mahar (2011) stated that children levels of physical activity are strongly tied to the chances they have to be active. In addition to physical education, schools have the capacity to affect students' physical activity behaviors through a variety of options (e.g., recess periods, classroom physical activity breaks, active transport to and from school; van Landeghem, 2003).

The researcher identified four lists for the students to choose from for the second question. These activities are birthday parties, playdates, playing online games, and other (should they select other, they must specify an activity or activities they do). The response descriptions for the four activities are shown in Figure 4. 


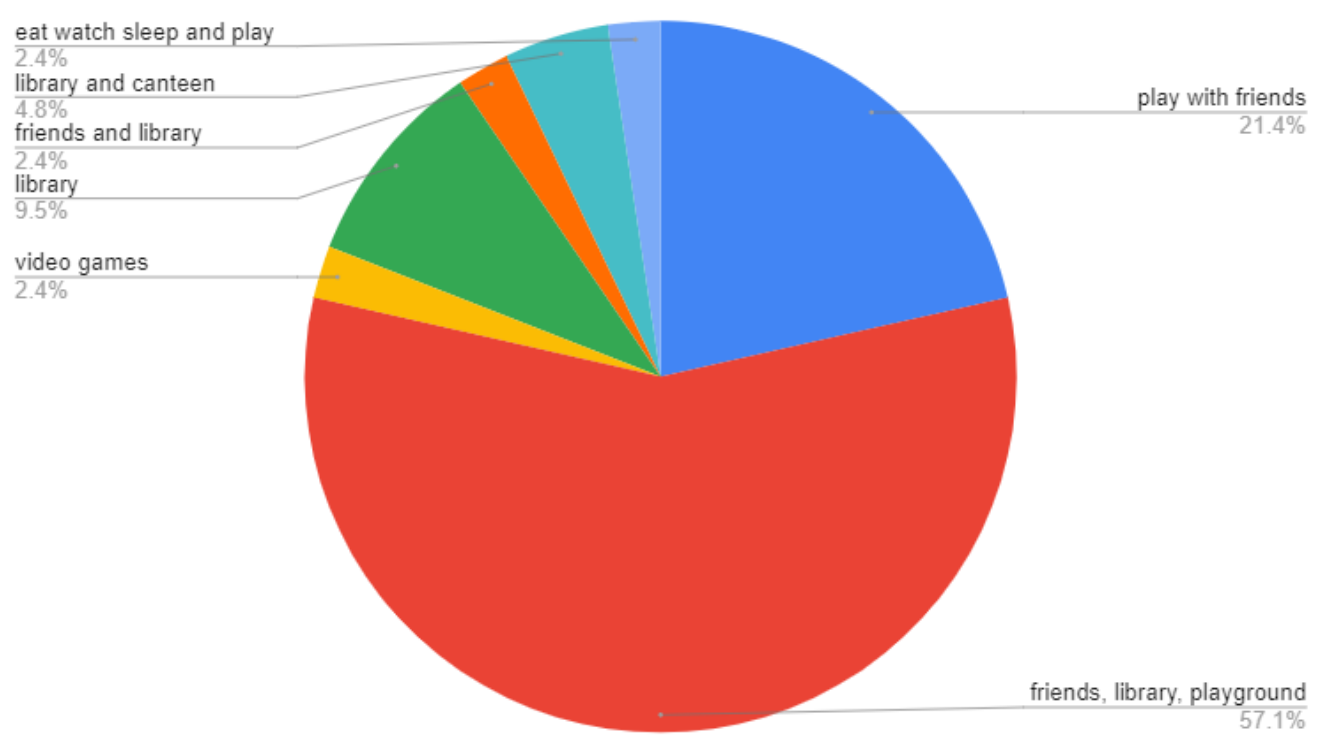

Figure 3. Students' activities in school during their free time before the pandemic.

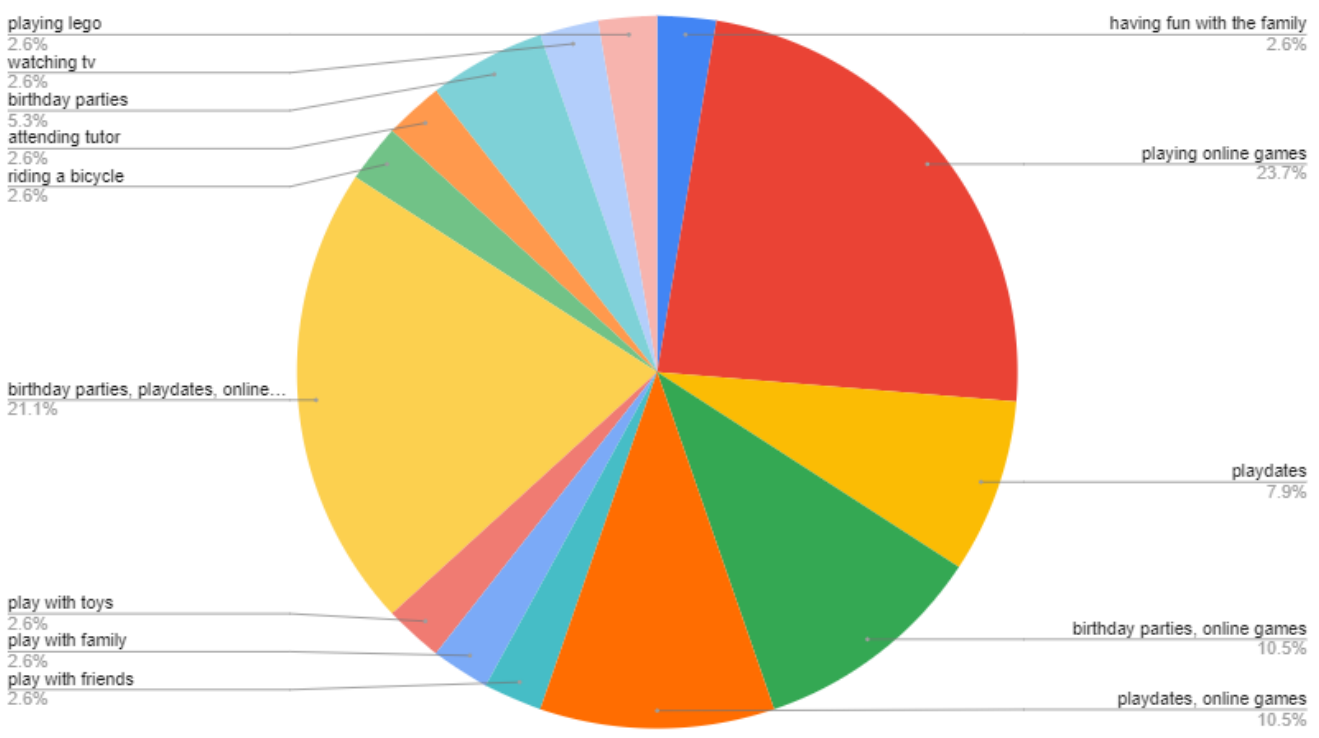

Figure 4. Students' activities at home during their free time before the pandemic.

Figure 4 shows that almost all respondents answered playing online games. Meanwhile, respondents also chose birthday parties, playdates, and playing online games as the second to the highest. The result found that students tend to prefer playing online games once at home. Rock implied that all of these devices are highly excellent at diverting individuals. As a result of this evolution, internet gaming was invented to provide individuals with amusement (2009). However, the students also favored physical activities like birthday parties and play dates next to playing online games. Students also indicated the activities they prefer, like playing Lego, watching TV, playing with toys, attending tutorial classes, and riding a bike.

The researcher retained the choices from question number two for question number three to compare students' activities at home before and during the pandemic.

R2: Figure 5 shows that $43.6 \%$ of the respondents chose playing online games. While $10.3 \%$ chose play dates, playing online games, and birthday parties. Students that play online games, according to Kuss and Griffiths, are just having fun. They do not simply play for the sake of having fun; they also play to feel relieved. Students sometimes feel anxious during the school day due to the amount of work they have to do, and playing helps relieve that tension (2012). With the new normal and limited social interaction, students tend to play online games. 


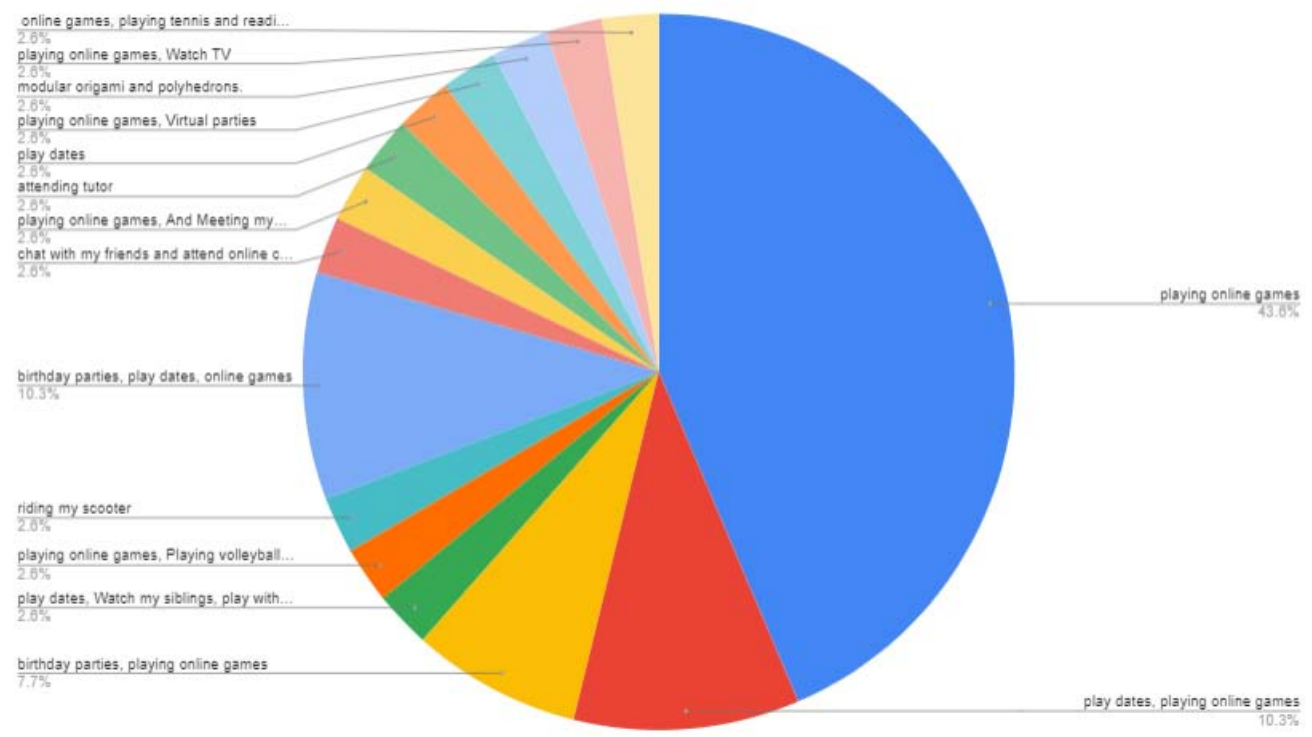

Figure 5. Students' activities during their free time at home during the pandemic.

Table 1. Students' suggested activities during their free time

\begin{tabular}{|c|c|}
\hline \multicolumn{2}{|c|}{ Suggested Activities During Free Time } \\
\hline School & Home \\
\hline Playing games with classmates and friends & $\begin{array}{l}\text { Playing online games with classmates and } \\
\text { friends }\end{array}$ \\
\hline $\begin{array}{l}\text { Playing Filipino games at school like } \\
\text { patintero because kids my age can learn } \\
\text { Filipino game in our country. }\end{array}$ & Swimming with classmates \\
\hline Read books & Read because it improves your skills \\
\hline Go to the library. & Play games. Do art. \\
\hline $\begin{array}{l}\text { Do seesaw tasks, so that at the end of the term } \\
\text { we will have a vacation earlier. }\end{array}$ & $\begin{array}{l}\text { Having a school Minecraft server so that the } \\
\text { kid will have more creativity because in } \\
\text { Minecraft you can build structures and we can } \\
\text { be creative in building those structures. }\end{array}$ \\
\hline $\begin{array}{l}\text { Play sports like volleyball and biking to make } \\
\text { them active and healthy. }\end{array}$ & Play and read books. \\
\hline $\begin{array}{l}\text { Read books and play with their classmates, } \\
\text { also study that he/she will not be confused. }\end{array}$ & Play with my sister \\
\hline Do homework. & Play online games with your siblings and rest. \\
\hline
\end{tabular}

Table 1 shows the different suggested activities of the students. These range from playing online games to physical and logical activities. Results show that playing online games was just one of the activities they prefer, most students were creative in suggesting activities that they like.

\subsection{Conclusion}

The students were asked to suggest fun and creative activities that can be done with or without the pandemic in school and at home. R3: The respondents came up with various activities, not just focusing on online games but activities that seemingly enhance their body and creativity and development of their thinking skills. The concrete-operational 
stage is an essential period in children's cognitive development (Piaget, 1947). According to Piaget, this stage of thinking is characterized by logical processes that allow for logical reasoning, such as conservation, reversibility, or classification.

\subsection{Recommendations}

The research indicated significant differences in students' activities before and during the COVID-19 pandemic, especially with activities involving physical, craft, and critical thinking. Students were more likely to choose activities that involve different movements and activities that spark their interest. This study only focuses on the students, involvement of the teachers and parents in the next cycle is highly encouraged. The research may help the stakeholders to gain a new perspective of fun and creative ways to improve activities for Grade 3 students, especially in this better normal.

\section{Acknowledgement}

I want to thank De La Salle Santiago Zobel School in the Philippines for their assistance and support. I'd also like to thank my family for their never-ending encouragement, support, and love.

\section{References}

Bauman, A. E., Sallis, J. F., Dzewaltowski, D. A., Owen, N. (2002). Toward a better understanding of the influences on physical activity: The role of determinants, correlates, causal variables, mediators, moderators, and confounders. Am. J. Prev. Med., 23, 5-14. https://doi.org/10.1016/S0140-6736(12)60735-1.

Coronavirus Disease (COVID-19) Pandemic. Front. Public Health, 8, 199. https://doi.org/10.3389/fpubh.2020.00199.

Czaja, R. and Blair, J. (2005). Designing surveys: A guide to decisions and procedures (2nd ed.). London: Sage.

de Vaus, D. (1995). Surveys in social research. St Leonards: Allen \& Unwin.

Gall, M. D., Gall, J. P., Borg, W. R. (2007). Educational research: An introduction (8th ed.). Boston: Pearson http://digilib.umpalopo.ac.id:8080/jspui/handle/123456789/260.

Jansen, K. J., Corley, K. G., and Jansen, B. J. (2007). E-survey methodology. In R. A. Reynolds, R. Woods, \& J. D. Baker (Eds.), Handbook of research on electronic surveys and measurements (pp. 1-8). Hershey: Idea Group Reference.

Kuss, Daria J. and Mark D. Griffiths. (2012). Adolescent online gaming addiction. Education and Health, 30 (1), 15-17. https://owl.english.purdue.edu/...resource/560/07/.

Mahar, M. T., S. K. Murphy, D. A. Rowe, J. Golden, A. T. Shields, and T. D. Raedeke. (2006). Effects of a classroom-based program on physical activity and on-task behavior. Medicine and Science in Sports and Exercise, 38(12): 2086-2094.

Mcleroy, K. R., Bibeau, D., Steckler, A., Glanz, K. (1988). An Ecological Perspective on Health Promotion Programs. Health Educ. Behav., 15, 351-377. https://doi.org/10.1177\%2F109019818801500401.

Piaget, J. (1947). The Psychology of Intelligence. Abingdon: Taylor and Francis.

Piaget, J. (1954). The development of object concept (M. Cook, Trans.). In J. Piaget \& M. Cook (Trans.), The construction of reality in the child (pp. 3-96). New York, NY, US: Basic Books. https://doi.org/10.1037/11168-000.

Ricci, F., Izzicupo, P., Moscucci, F., Sciomer, S., Maffei, S., Di Baldassarre, A., Mattioli, A. V., Gallina, S. (2020). Recommendations for Physical Inactivity and Sedentary Behavior During the Coronavirus Disease (COVID-19) Pandemic. https://www.frontiersin.org/articles/10.3389/fpubh.2020.00199/full.

Rock, Dave. (2009, October 4). Easily distracted: why it's hard to focus, and what to do about it. https://www.psychologytoday.com/.../200910/easily-distracted-why-its-hard-focus-and-what-do-about-it.

Sallis, J. F., Cervero, R. B., Ascher, W., Henderson, K. A., Kraft, M. K., Kerr, J. (2006). An ecological approach to creating active living communities. Annu. Rev. Public Health, 2006, 27, 297-322. https://doi.org/10.1146/annurev.publhealth. 27.021405.102100.

van Landeghem, K. (2003). Preventing obesity in youth through school-based efforts. Washington, DC: National Governors Association Center for Best Practices, Health Policy Studies Division.

Walter, M. (2010). Surveys. In M. Walter (Ed.), Social research methods (2nd ed., pp. 151-183). Melbourne, Victoria: Oxford University Press. 